\title{
Stranded 'Birds of Passage'? ERITEAN AND ETHIOPIAN REFUGEES IN KHARTOUM
}

\author{
Gaim Kibreab, University of Uppsala, Sweden
}

\section{INTRODUCTION}

The government of Sudan has consistently accepted refugees on a humanitarian basis since the mid 1960s. The refugees in the country are in: (i) reception centres; (ii) organized wageearning and semi-urban settlements; and (iii) urban and rural areas where refugees have self-settled among the local population. The main concern here is the self-settled urban refugees, with more emphasis on those in the capital, Khartoum.

In the beginning of 1989 there were a total of 770,000 refugees throughout the country. Among them, 60,000 were from Uganda and 5,000 from Zaire residing in Southern Sudan. Another 75,000 Chadian refugees were in Western Sudan. The majority, about 630,000, were in the Eastern and Central regions, and were all from Eritrea and Ethiopia; there is no breakdown of the proportion, but the majority are Eritreans. Of 770,000 refugees, only $38 \%$ were assisted by the UNHCR as of 31 July 1988 . The others managed their own affairs by sharing whatever services were available to Sudanese nationals. Among the 630,000 Ethiopian and Eritrean refugees in the Eastern and Central regions of the country, about $25 \%$ are in organized wage-earning and semi-urban settlements. Another $17 \%$ are in transit centres living on international aid and about $60 \%$ are spontaneously settled. These data are, however, indicative rather than conclusive.

Self-settled or spontaneously settled refugees are not provided with any kind of assistance. They are scattered both in the rural and urban areas. According to government sources, there are about 210,000 refugees in urban centres (Khartoum: 45,000; Gedaref: 35,000; Kassala: 50,000; Port Sudan: 50,000 and another 30,000 in the small towns of Es Showak, Wad Madeni and Damazin with about 10,000 in each). A

recent census of the refugee population in Khartoum, however, found that the total number of refugees in the capital was about 35,000 instead of 45,000 . Even though the census was based on a total enumeration, it is reasonable to expect some refugees may have evaded the census.

\section{GOVERNMENT POLICY ON URBAN REFUGEES}

Generally the Sudanese Government has one of the most generous refugee policies in the world. Despite economic difficulties caused by a range of factors such as civil war in the South, drought, unfavourable terms of trade, declining productivity in all

\section{It is not clear how the government intended to distinguish war victims from drought victims. In the refugees' countries of origin, war and environmental degradation are interwoven.}

sectors of the economy, debt burden etc., its doors still remain open. Until 1988 even environmental refugees (those whose flight was prompted by severe environmental degradation) were provided with succour. After 1988, however, there has been an intention, at least at a policy level, to refuse entry to those who flee their countries of origin due to environmental degradation which poses a threat to their lives. For instance, the Minister of Refugees, during his visit to the Eastern region, instructed the authorities in the area and in the Central region not to admit additional refugees. He stated that "refugee status is to be granted only to war victims."
It is not clear how the government intended to distinguish war victims from drought victims. In the refugees' countries of origin, war and environmental degradation are interwoven. Similarly unclear is how the government's new policy has affected the inflow of new asylum seekers. According to the General Project Manager, Syd H. M. Osman, the new restrictive policy had resulted in a considerable decrease in the number of new arrivals.

Some evidence suggests that the government was determined to implement its restrictive refugee policy. For example, on January 15, 1988 the newspaper, Ayam, reported that "concerned authorities in the Eastern region have refused to grant asylum to 30 Ethiopians". According to COR authorities, the decision was based on the country's new policy towards refugees (Ayam, Issue 6230, Jan. 15, 1988). However, there is no concrete evidence showing that the country's refugee policy has become more restrictive than it was in the past.

Even though it has accepted refugees from neighbouring countries in the past threedecades, Sudan has always attempted to place all refugees in organized camps and settlements. One concern has been national security. The most important reason seems to be the minimization of the strain such a large influx of refugees may cause on the country's economy, social services and common property resources such as water, grazing and woodlands. By placing refugees in spatially segregated sites, the government wants to achieve two things. First, it wants to discourage the refugees from competing with nationals for scarce natural resources, employment opportunities, consumer goods and physical and social services. Second, it wants the international donor community to meet their needs until they voluntarily return to their countries of origin. 
The Asylum Act of 1974, which regulates refugee status in the country embodies the basic principles of the 1951 United Nations and the 1969 OAU Conventions. Not only is it seen as generous, but it is also viewed as a model legislation for emulation by other Third World countries. However, there are certain serious restrictions which, on the one hand, influence the future anticipation of refugees, and, on the other, constrain the ability of refugees to engage in meaningful economic activities commensurate with their skills and previous work experiences.

Section 10(2) of the Asylum Act forbids a refugee to leave a place of residence specified for him/her by the authorities concerned. This constitutes a serious deprivation of freedom of movement. Formally, the government can legally restrict the freedom of movement of refugees within its territories by making reference to Art. 26 of the 1951 Convention as stipulated in Art. 42 of the same Convention. The deprivation of the right of freedom of movement imposed by section 10(2) of the Asylum Act is, however, inconsistent with the recommendations of the 1979 Arusha Conference and with the spirit of the OAU Charter of Human and People's Rights (see Recommendation 5 of the Arusha Conf. and Art.12.1 of the Charter).

As indicated, most refugees in Eastern and Central Sudan are selfsettled. Formally, residence outside organized centres is illegal and refugees who reside outside the camps or settlements without authorization are subject to harassment, detention, fine and deportation to remote rural areas. According to the Regulation of the Asylum Act, refugees must register upon entry, but the overwhelming majority do not, mainly for fear of being sent to the reception centres in the unfamiliar rural areas or because the authorities do not insist on registration. Refugees with urban backgrounds see no future in the rural camps or settlements. They try to avoid relocation by not reporting to the authorities upon arrival. The majority are self-settled without proper documents. Legally, they are not refugees because their status is not determined by the authorities concerned.

Sudan's settlement policy appears extremely unrealistic because it does not take into account the huge amount of capital and natural resources required to implement such a policy. It seems that the government is aware of its inability to implement its own policy. The awareness of this may have led to its tolerance of spontaneous settlement by the refugees in the urban areas without formally sanctioning it. However, as long as Sudan does not officially sanction spontaneous settlement of refugees in the urban centres, such tolerance only

\section{Whenever aggrieved, they cannot seek redress from formal government structures because they are not legally entitled to reside in the urban centres.}

paves the road to abuse by municipal and police authorities.

Technically, unregistered refugees have no legal rights. They are not entitled to protection or work. They are not allowed to engage in income-generating activities, nor do they have access to public amenities. Yet, not only is there no single case of refoulement, but a considerable proportion do engage in income-generating activities (wagelabour, trade, etc.), send their children to school, enjoy access to the available health services, etc. without being formally entitled to such rights.

However, since such entitlements cannot be claimed by the refugee communities by right, access can be denied arbitrarily by municipal authorities. Refugees pay bribes to secure residence and work permits or to escape harassment for illegal residence in the urban areas. By adopting a policy which it cannot implement, the government has unintentionally rendered the refugee communities vulnerable to the whims of corrupt bureaucrats, police officers and municipal authorities. Despite its determination, the government has not been able to phase out spontaneous settlement.

The effects of this unrealistic policy have been detrimental to both the country and the refugees. If refugees were allowed to participate freely in the economic life, they would have contributed to Sudan's social progress and economic growth. One constraint faced by the ind ustrial sector is high turnover of Sudanese skilled labour to the Gulf States (Bank of Sudan: 1980;1987). The uninhibited participation of refugees in the labour market may partially overcome the skilled manpower bottleneck in Sudan. Sudan has not invested in education or training of refugee labour. Refugees would have represented an asset if the government had a policy that favoured tapping such a resource.

Many refugees have never lived in rural areas, but government policy does not take this into account. All refugees, regardless of their social or professional backgrounds, are expected to stay in camps or settlements in rural areas. As long as the government does not address the question of urban settlement, its policy will not only remain ineffective, but it will exacerbate the plight of the self-settled refugees.

The government says it does not want refugees in urban centres, but it has no place for them elsewhere. It is not willing to provide assistance to refugees and it also does not allow aid agencies to fulfil this function for fear of attracting more influx from the rural areas. Refugees can only survive by engaging in income-generating activities to which they are not formally entitled.

Their weak legal status has, therefore, made their position extremely vulnerable. They are often harassed by corrupt police and security officers who threaten them with deportation to the rural areas. To escape this, refugees are often forced to pay bribes in cash or services. Greedy employers take advantage of their undocumented position and landlords also charge them exorbitant rents. Whenever aggrieved, 
they cannot seek redress from formal government structures because they are not legally entitled to reside in the urban centres. Fear of deportation to rural areas is universal, and problems are often solved through an informal network of inter-personal relations which are often biased in favour of those who have better contacts and resources.

Fearing deportation to rural areas and not seeing any future for themselves or their children in Sudan, most refugees are too insecure to make investments in the cities. Aid agencies have also been reluctant to alleviate their plight because they are discouraged by the government. The majority of the agencies are also reluctant to provide assistance to refugees in urban areas because they do not consider their situation as stable.

Consequently, most refugees in Khartoum dream of returning home or emigrating to the Gulf states or to the West. Among 500 refugee household heads I interviewed in Khartoum, less than $20 \%$ of the Eritrean refugees were planning to stay in the Sudan until the circumstances in connection with which they fled their country were eliminated. Among Ethiopian refugees, none thought of either returning home or staying in Sudan, but did dream of migrating to OECD countries.

Other researchers have also found the same results. H. Schönmeier, for example, states:

Almost all the refugees in Khartoum would like to leave their present location. The majority of them would like to leave the Sudan either in the direction of the Gulf States or of the northern industrial states (1988).

A. Pezaro also states that all her interviewees, except two, wanted to be resettled in the Western industrialized countries. Not only that, but most of her women interviewees preferred not to give birth in the Sudan. She further states:

Some of them even excluded marriage from their future plans as long as they cannot either go back to Eritrea or leave for resettlement. This was partially ascribed to the economic problems they faced, but a more important factor seems to be the feeling that there is no future for the children if they are born in a situation of being somewhere "in-between" or not really at home (1987).

Other studies confirm the refugees in urban areas perceive no viable points of reference to plan for a new life in the Sudan.

Some reports claim a discernible difference between attitudes of Moslem and Christian refugees regarding willingness to put roots in Sudan. A 1984 report by the US Embassy in Khartoum, for example, states that the Moslem refugees in Port Sudan have successfully acculturated and have ceased to be refugees except in a technical sense.

What the report overlooks is that the factor which has facilitated adaptation of the refugees is not religion as

\section{Theoretically, a community that sees no future in a certain environment would be expected to be resigned and lethargic, but available evidence shows that the majority of refugees are hard- working, resilient and creative.}

such, but common ethnicity between the host society and the refugee community. Religion was not decisive. Moslem refugees from the Eastern low lands and the Eritrean highlands are as alienated as their Christian brethren in all the urban centres of Sudan. Among the refugees in Kassala, T. Kuhlman found ethnicity as one of the factors that facilitate refugee integration. In areas where there is no common ethnicity between the host and the refugee population, as in Khartoum, there is no discernible difference of attitude between Moslem and Christian refugees regarding future anticipation. This is noted in all the available studies.

In Pezaro's study, the refugee women, who were unwilling to give birth and who excluded marriage from their future plans as long as they remained in Sudan, were Moslems. Respondents in my study comprised Moslems and Christians and there was no discernible difference regarding determination to leave the Sudan. All were equally determined to leaveSudan, given the chance.

Yet despite the fact that the overwhelming majority of the refugees saw no viable future in Sudan, they kept on applying for extremely limited resettlement opportunities without being discouraged by rejections; the majority leave no stone unturned to earn an income both for survival and saving to facilitate departure from Sudan. Most activities they engaged in were far below their qualifications and skills.

Theoretically, a community that sees no future in a certain environment would be expected to be resigned and lethargic, but available evidence shows that the majority of refugees are hardworking, resilient and creative. What underlies the unwillingness to stay in Sudan? In addition to the unfavourable government policy towards refugees, already discussed, additional likely factors spring to mind: (1) Lack of international assistance; (2) Cultural incompatibilities; (3) lack of economic opportunities; (4) exaggerated expectations of opportunities in the industrialized countries. These are in turn discussed in the following.

\section{LACK OF ASSISTANCE}

When a refugee leaves his/her country of origin, there is always an expectation of a better future not only in terms of physical safety and security, but also in terms of material assistance at least at the initial stage. There is an expectation of an organized reception. On arrival, the refugee concerned finds out that s/he has to rely on her/his own ingenuity both for survival and for acquiring the necessary documents to be able to proceed to the border towns.

For many, the movement does not end at the border towns, but a considerable number aim for the capital city - Khartoum - and from there to the Gulf States or Western Europe, Canada, USA and Australia. For the majority, this represents an up-hill task which may never materialize. Whether one succeeds with such tasks is determined by the amount of money, personal 
contacts with Sudanese authorities, influential refugees, relatives and friends both within and outside the Sudan. Those refugees who lack the necessary financial resources and/or social networks often fall easy prey to corruption and abuse. The majority of the refugees belong to this category. Those who take advantage of such

For example, a woman whom they see greeting a man in the street, or a woman who does not wear a tobe (veil) is likely to be mistaken as a prostitute.

vulnerable groups are not only Sudanese, but also refugees who work independently or with Sudanese. As will be revealed in the following discussion, the situation is more burdensome to women.

The absence of organized reception is exacerbated, as we saw earlier, by a government policy which forbids refugees from residing in the urban centres. For the majority, residence in the urban areas is crucial, not only because the urban environment is familiar, but it is only if they live in the urban centres, mainly Khartoum, that their dream of emigration to the Gulf States or to the OECD countries may materialize.

All the embassies are situated in Khartoum. For the majority, residence in the capital is only possible either by obtaining documents through nonformal channels (through payment of bribes) or by evading controls. The groups that victimize them are aware of their vulnerability and use different means to force them into social networks of dependence. Emigration, especially to the OECD countries, is, therefore, perceived by the majority as a form of liberation from being socially degraded and cconomically exploited.

\section{CULTURAL DIFFERENCES}

Civil society is more secularized in Ethiopia and Eritrea than in the Sudan.
In Sudan social norms, values and gender relationships are defined by Sharia. The dominant culture is Islamic and rigidly paternalistic. Roles are defined with a very low degree of tolerance for non-conformity, especially when the non-conformist is a woman. Refugees come from patriarchally and paternalistically determined social organizations, but these are not on the same level as in Sudan. Compared to Sudan, cultural pluralism, at least in urban centres, is relatively more tolerated in the refugees' countries of origin. All schools are open for both men and women from early childhood. Women socialize relatively freely with men, not only in private, but also in public spheres. Sudanese society, at least the Islamic north, is rigidly divided along gender lines and there are rules which govern interaction between the sexes. Non-conformity to these tacit and explicit rules, especially by women, often leads to ostracization and humiliation.

Eritrean and Ethiopian refugees, regardless of their religious affiliations, do not fit easily into this cultural pattern. The reason for this does not only derive from original cultural dissimilarities between the two societies, but also from the drastic changes refugees undergo in lifestyle as a result of flight. When young refugees flee their country, they not only escape persecution, but also authoritative parental controls. Young refugees, who were socialized to conform to norms and to accept the values and standard behaviour of their society, find themselves suddenly freed from such authoritarian socialization mechanisms.

In the new environment, they try to enter into inter-personal relationships which would have not been allowed even in their countries of origin. For the host society the cultural contrasts, namely the behaviour patterns, the norms, thought and belief habits of the refugees, become too radical to the extent of being considered as a threat to cultural hegemony. To many conservative Sudanese, the behaviour of refugee women is considered to be unacceptable and dangerous. They fear that emulation of such behavioural patterns by
Sudanese youth, especially by young women, may "contaminate the cultural purity" of Sudan.

For example, a woman whom they see greeting a man in the street, or a woman who does not wear a tobe (veil) is likely to be mistaken as a prostitute. Pezaro, in her study of the situation of Eritrean refugee women in Khartoum, found that the way Eritrean women handled the rules that govern gave rise to conflicts in daily life in which:

refugee women have to be afraid of their reputation, if they - as they are used to in Eritrea - talk or interact in an "easy" way with Eritrean as well as with Sudanese men. They [the refugee women] complain about being considered either as potential marriage candidates by certain Sudanese boys or as prostitutes. They feel, therefore, restricted in their leisure-time activities or generally in their freedom of movement $(1987,15)$.

The response of refugees is varied and the factors influencing the nature of their responses are quite complex. In the short-run, however, many refugees tend to make some modifications in their behaviour, especially in those aspects "detestable" to the dominant culture. Generally, however, they tend to cling to their former way of life, especially when no serious costs are to be incurred or serious consequences to be suffered as a result. On the whole, the refugee communities constitute distinct and separate communities in the different residential areas of Khartoum.

The intolerance of the dominant culture to non-conformism is considered by many refugees as constituting a fet.er to social progress for which, in their view, no solution exists, other than emigration either back to their countries of origin or to the OECD countries.

In my study, among the refugees in Khartoum, I found discernible differences in terms of perceived solutions entertained by Ethiopian and Eritrean refugees. For the Ethiopian refugees, the only solution they perceived was emigration to the OECD countries, while for the majority of the Eritreans, repatriation following the elimination of the circumstances in connection with which they fled their 
country was the most acceptable solution. Emigration to the OECD or the Gulf countries was preferred only if the circumstances in their countries remained unchanged. Another difference which emerged from the results of the study was that while none of the Ethiopians wanted to stay in Khartoum, some Eritreans said they would be willing to stay if the government changed its restrictive policy towards urban refugees.

The Sudanese seem to consider their culture superior to those of the refugee communities. As a result, they look upon the behavioural patterns of the refugees with contempt. Karadawi states:

The Sudanese core-culture despises what is considered as the moral laxity of the refugees. The incomplete family life, unrestricted movement in town and the liberated socialization by females are both alien and detestable to the reserved, male-dominated and chauvinistic Khartoum society (1978, 19)).

It is noteworthy to point out that many of the refugees looked down upon the Sudanese way of living. A considerable number of the refugees I interviewed had an oversimplified view of the Sudanese lifestyle. For example, the seclusion of women from public life and the extreme male domination that characterizes Sudanese culture was seen as being oppressive and backward. For a large proportion of the refugees, language also represents a serious barrier, because a large majority, especially among the Ethiopians, do not speak Arabic.

The consequence was that, for the majority of refugees, an alternative long term solution outside such a society was seen as being more preferable, rather than radically modifying their culture to fit with the styles of living of their host society. Sudan is viewed by the majority as a stepping stone for further emigration. In fact, even though the argument may sound counterfactual, one may safely assume that no matter how favourable the cultural environment in Sudan may have been, there would still be some who would wish to emigrate to the OECD countries, given the chance. It can be said that this category came to the
Sudan due to sheer geographical proximity and not to seek durable asylum.

\section{LACK OF ECONOMIC OPPORTUNITIES}

Agriculture is the backbone of the national economy of the Sudan, which contributes about $35 \%$ to GAP. Over $90 \%$ of the country's total export earnings derive from it. About $80 \%$ of the population is dependent for its livelihood on the sector (The Six Year Plan of Economic \& Social Development: 1977; Kibreab: 1987).

The manufacturing sector presents a small fraction of the national economy not only in terms of contribution to GAP, but also in terms of the amount of labour employed. Between 1982/83 and 1986/ 87 , the contribution of manufacturing and mining to GAP was only $7 \%$ (Bank of Sudan: 1987). The industrial sector has been suffering from serious problem of under-utilization of capacity throughout the 1980s due to obsolete and inefficient machinery, failure in electric power, shortages of supply of raw materials and spare parts, high skilled labour turn over to the oil-rich Gulf States, inefficient

The material standard of living in the OECD countries compared to that in the Sudan is also higher, and relatives abroad genuinely believe that the living conditions of their relatives would considerably improve if they joined them.

management, and transportation bottlenecks (Bank of Sudan: 1980; 1986; 1987; The Six Year Plan of Economic and Social Development: 1977). The level of capacity under-utilization in the industrial sector, in the 1980s, has been estimated at 20-40\% (Bank of Sudan: 1985).

The fact that the modern manufacturing sector constitutes a small fraction of the national economy and suffers from reduced production capacity suggests that employment opportunity in the urban sector is either little or non-existent. The consequence of this for the refugees' possibility to be absorbed in the modern industrial sector is extremely limited. The lack of employment opportunity in the urban sector is also, as indicated earlier, exacerbated by language difficulties. Since one of the constraints on industrial production is emigration of skilled labour to the oil-rich Gulf States, the presence of skilled individuals among the refugee population would have, under favourable government policy, filled the vacuum created by the departure of the Sudanese skilled labour force. This is, however, blocked partly by structural problems, such as lack of knowledge of Arabic, but above all by the stubborn resistance of the labour unions to open up membership to the refugees. The exclusion of union membership has in effect meant denial of entry into the industrial labour market (see Document of the Office of Refugee Affairs, US Emb.: 1983; 1984). The majority of the refugees in Khartoum are mainly employed in the service sector often in activities which do not correlate to their skills and past work experiences. Most of the refugee women are, for example, engaged in domestic labour regardless of their education or professional background.

Even though there are some selfemployed refugees in the informal sector, there are a whole range of structural problems which constrain effective refugee participation (Kibreab: forthcoming). These limited employment and other economic opportunities create, on the part of the refugees, a sense of pessimism. As a result, many see no future either for themselves or their children in the Sudan. Consequently, they become obsessed either with dreams of repatriation to their home country or resettlement in one of the OECD countries.

\section{EXAGGERATED EXPECTATIONS}

A considerable proportion of the refugees in Khartoum have relatives in the OECD countries. One would, therefore, expect them to have some information about the kind of life awaiting them in the countries of 
resettlement. Judging from the data elicited among the refugees in Khartoum, I was struck by their level of ignorance in this regard. The majority had an oversimplified picture of life in the OECD countries. They perceived life in the countries' of resettlement as being free of problems. This is attributable to many factors. Most of the refugees in the capital havehad, since their childhood, a lifestyle which is uncritically Western-oriented. This orientation is further reinforced by their to the core culture in Sudan, which is increasingly influenced by Islamic fundamentalism. Their relatives do not give them a true picture of the living conditions in the OECD countries. Several factors account for this. It is unusual among such communities to tell bad news to relatives in distant places for fear of creating worry and anxiety. The general tendency is rather to tell one's relatives that everything is fine even when this is not true. The material standard of living in the OECD countries compared to that in the Sudan is also higher and relatives abroad genuinely believe that the living conditions of their relatives would considerably improve if they joined them.

\section{REFERENCES}

Ayam, (Newspaper in Arabic), Khartoum, Sudan.

Bank of Sudan, 1980, 1983, 1985, 1986 and 1987 Annual Reports. Khartoum, Sudan.

Ministry of National Planning (1977). The Six Year Plan of Economic and Social Development 1977/78 - 1982/83, Vols. I\&II. Khartoum, Sudan.

Duda, G. R. (1985), Dynamics of the Refugee Experience: Psychological Functions of Future Anticipations. Paper presented to the First IACCP Circum-Mediterranean Conference on "Ethnic Minorities in Europe", June 25-28, 1985 Malmö, Sweden.

Government of Sudan (1974). The Regulation of Asylum Act, 1974, Act No. 45, Sudan Gazette No.1162.

Karadawi, A. A. (1978). A Note on Urban Refugees in the Sudan, 1975 - 1978, Office of the Commissioner for Refugees, Ministry of Interior, Khartoum, Sudan (mimeo).

Kibreab, G. (1987). Refugees in the Sudan Urban Areas with Emphasis on Khartoum

Kuhlman, T. (1990). Burden or Boon? A Study of Eritrean Refugees in the Sudan. Amsterdam.
Nobel, P. (1982). Refugee Law in the Sudan, Research Report no. 64. Uppsala: SIAS.

Office of the Commissioner for Refugees (1989). Monthly Statistical Reports, Khartoum, Sudan

Pezaro, A. (1987), Refugee Women Research in Khartoum - Preliminary Report, Sociopsychological Research Center on Development Planning - University of the Saar, FRG (mimeo).

Schönmeier, H. (1988), Eritrean Refugees in the Sudan: Waiting to return or start a new life? (mimeo).

Seyyasa, (Newspaper in Arabic), Khartoum, Sudan.
ShowakMagazine(1988). Interview with Syd Hassen M. Osman, General Project Manager, Es Showak, Aug/Sept.

The Recommendations from the Arusha Conference on the African Refugee Problem (1979).

UNHCR 1988). Briefing Note on Refugees in the Sudan, Branch Office, Khartoum, Sudan.

United Nations (1951) Convention Relating to the Status of Refugees

USEmbassy (1983), Refugee Situation in Sudan, Office of Refugee Affairs, Khartoum, Sudan (mimeo).

US Embassy (1984), Refugees in Sudan's Urban Centres, Office of Refugee Affairs, Khartoum, Sudan (mimeo).

\title{
CONFERENCE OF THE CANADIAN ASSOCIATION OF AFRICAN STUDIES
}

\author{
YORK UNIVERSITY \\ TORONTO
}

\section{MAY 16 - 18, 1991 \\ THE MAIN THEME AFRICA IN THE 1990s: DEVELOPMENT WITH DEMOCRACY}

There will be a stream of consecutive sessions on refugee related issues. The topics include:

- African Refugees in the Era of the UNHCR's Crisis

- Repatriation of the ANC and its Effects on Democracy in South Africa

- African Political Crisis

- Refugee and Resttlement

- Women Refugees

Inquiries to:

Mr. Ogenga Otunnu

Centre for Refugee Studies, York University

4700 Keele St., North York,

Ontario, Canada M3J 1P3

Tel: (416) 736-5663

Fax: (416) 736-5837 